\title{
EVALUATION OF ANTI-INFLAMMATORY AND ANTI-ARTHRITIC POTENTIAL OF FRACTIONS OF ECLIPTA PROSTRATA LINN
}

\author{
HITESH MALHOTRA ${ }^{1 *}$, MANJUSHA CHOUDHARY ${ }^{2}$
}

${ }^{1}$ Department of Pharmaceutical Sciences, Chandigarh College of Pharmacy, Ajitgarh, Punjab, India. ${ }^{2}$ Department of Pharmaceutical Sciences, Kurukshetra University, Kurukshetra, Haryana, India. Email: hiteshmalhotra03.hm@gmail.com

Received: 18 March 2019, Revised and Accepted: 16 May 2019

\section{ABSTRACT}

Objective: The objective of the study was to establish the anti-inflammatory and anti-arthritic potential of various fractions of Eclipta prostrata Linn.

Methods: The four fractions, i.e., n-butanol, ethyl acetate, chloroform, and n-hexane from hydro-alcoholic extract were obtained. First, the fractions were evaluated through in vitro models, and then they were evaluated by in vivo anti-inflammatory model, i.e., carrageenan-induced paw edema model. Further, two active fractions were evaluated for the anti-arthritic activity using formaldehyde induced arthritis model.

Results: The fractions at a dose of 100 and $200 \mathrm{mg} / \mathrm{kg}$ showed an anti-inflammatory activity, but the ethyl acetate and chloroform fraction will show maximum anti-inflammatory potential. Hence, they are further evaluated for anti-arthritic potential where they show significant activity.

Conclusion: From the results, it is concluded that the ethyl acetate and chloroform fraction show significant anti-arthritic activity.

Keywords: Inflammation, Arthritis, Eclipta prostrata, Wedelolactone.

(C) 2019 The Authors. Published by Innovare Academic Sciences Pvt Ltd. This is an open access article under the CC BY license (http://creativecommons. org/licenses/by/4. 0/) DOI: http://dx.doi.org/10.22159/ajpcr.2019.v12i7.33009

\section{INTRODUCTION}

Arthritis and diseases of joints have been plaguing humankind since times. There is an indication of rheumatoid arthritis (RA) in the Egyptian mummies, as found in several studies. G. Elliot, in his studies, found that RA was a prevalent disease among Egyptians [1]. In Indian literature, Charak Samhita (300-200 B.C.) also described a clause that describes pain, joint swelling, and loss of joint morbidity, and functions. RA is a continual autoimmune disease characterized by joint swelling, synovial inflammation, and cartilage destruction and commonly leads to significant disability [2]. It affects about $1 \%$ of the population of the world.

The pathophysiological changes in RA include hyperplasia of the synovial membrane, permeation of inflammatory cells, and neovascularization, which eventually lead to cartilage erosion and articular destruction. Moreover, the etiology is disappointingly understood now, but inflammatory cytokines are considered to play a key role. One of the critical pathogenesis of RA is the over-look of inflammatory cytokines, including tumor necrosis factor-alpha, interleukin-1 beta, interleukin-6, interleukin-33, and rheumatoid factor in synovial membrane and serum [3]. Various mediators which are secreted by macrophages and other immune cells will be regulated, and modulation of arachidonic acid metabolism by inhibiting enzymes such as cyclooxygenase and lipoxygenase are main targets for chronic inflammatory conditions. However, various categories such as immunosuppressants, nonsteroidal anti-inflammatory drugs, and steroidal anti-inflammatory drugs are currently being used, but their side effects limit their use. Due to these reasons, growing concern exists for the development of a new safe, potent, and less toxic anti-arthritic drug. Hence, there is a must to discover for more naturally available drugs so that their therapeutic values can be assessed and expanded [4].

The genus Eclipta was described by Linnaeus, with three species, i.e., Eclipta erecta L., E. prostrata L., and Eclipta punctuate L. Eclipta species are characterized by being usually perennial herbs, found in damp or boggy situations, often on stream and lakesides and then facultative semi-aquatic, with vertical emergent flowering branches. The plants of this genus composed of numerous phytoconstituents and are utilized comprehensively in folk medicine and pharmaceutical industries [5]

E. prostrata is commonly known as bhringaraj and belongs to family Asteraceae. The word prostrata was derived from Latin word Prostratus, which refers to annual, weak, sprawling stems arising from a perennial, and woody rootstock. It is an erect or decumbent perennial herb, 30-60 cm tall having weak and scabrous stems. The plant is widely distributed in pantropical and warm temperate areas of South America. In Australia it is widespread in Queensland, Northern Territory, and north-east New South Wales; in Western Australia rare in the Kimberley and near Perth. It is commonly found in India, China, Taiwan, Philippines, Japan, and Indonesia. E. prostrata (L.) consists of nicotinamide about $0.08 \%$, tannins, Vitamin A, ecliptine, and thiophene such as compounds such as triphenylmethanol and its acetate such as (2-[Buta-1, 3-diynyl]-5-[but-3-en-1-ynyl] thiophene) and (2[Buta-1, 3-diynyl]-5-[4-chloro-3-hydroxy but-1-ynyl] thiophene). Leaf extract mainly contains wedelolactone, demethylwedelolactone, demethylwedelolactone-7-glycosides, $\alpha$-terthienylmethanol, and $\alpha$-formyl-alpha-terthienyl, etc. The different parts of the plant such as leaves, roots, stems, and barks are used as antibacterial, antivenom, hepatoprotective, antihemorrhagic, anti-inflammatory, bronchodilator, anticancer, antiviral, analgesic, and antioxidant. According to Ayurvedic philosophy, E. prostrata is useful in inflammation, hernia, eye diseases, bronchitis, asthma, leukoderma, anemia, heart and skin diseases, blindness, and syphilis. The plant possesses various pharmacological activities, which include analgesic, hepatoprotective, hypoglycemic, hypolipidemic, hair growth promoting, antimicrobial, antimalarial, and anticancer activity [6].

\section{METHODS}

\section{Procurement and authentification}

Leaves of E. prostrata L. were collected in the month of November 2013 from the campus of Kurukshetra University, Kurukshetra, Haryana, 
India. Sample of leaves was authenticated by Dr. B. D. Vashistha, Chairman Department of Botany, Kurukshetra University, Kurukshetra, Haryana, India. For the purpose of any future reference, plant sample has been kept in the herbarium of the Department of Botany, Kurukshetra University under voucher specimen number KUK/BOT/IPS/17.

\section{Preparation of hydro-alcoholic extract and fractions}

Leaves of E. prostrata were washed under running tap water and dried under shade at room temperature for around 2 weeks. The dried leaves were ground into a coarse powder using pestle and mortar and stored in an airtight container. The powder was extracted with the opposite quantity of hydro-alcohol in a ratio of 30:70 by Soxhlet extraction at a temperature of $65^{\circ} \mathrm{C}-75^{\circ} \mathrm{C}$. The extract obtained was solidified and further subject to fractionation using the method as described by Suffness and Douros (1979). The fractionation was done using four solvents using n-hexane, chloroform, ethyl acetate, and n-butanol. The extract was initially dissolved in 1:1 mixture of $n$-hexane and distilled water and the two phases were separated in separating funnel. After $24 \mathrm{~h}$, the two layers were separated and the solvent was removed from the n-hexane layer to obtain the n-hexane fraction (EPHF). To the water fraction equal quantity of chloroform was added and allows separation of two layers in separating funnel. After $24 \mathrm{~h}$ again, two layers were separated and similarly Chloroform fraction (EPCF) was obtained. Further, the water fraction was mixed with an equivalent volume of ethyl acetate in a separating funnel to obtain the Ethyl acetate fraction (EPEAF). Finally, the water fraction n-butanol was added in the same volume and allows separation in a separating funnel for $24 \mathrm{~h}$. Thus, we obtained the n-butanol fraction (EPBF).

\section{Preliminary phytochemical screening}

The fractions obtained from the hydroalcoholic extract were subjected to preliminary phytochemical screening. About $5 \%$ solution of all the samples was prepared and filtered [7].

\section{Animals}

Wistar strain of albino rats (180-20 0g) was obtained from National Institute of Pharmaceutical Education and Research, Mohali. The animals were housed in the animal house of Institute of Pharmaceutical Sciences, Kurukshetra University, Kurukshetra. The animals were maintained under standard environmental conditions and were fed with standard pellet diet and water ad libitum. The study was approved by the Institutional Animal Ethics Committee (Reg. No. 263).

\section{Dose preparation}

The dose was selected on the basis of acute toxicity studies conducted on Wistar rats. The dose that should be administered to animals for the experiment would be 100 and $200 \mathrm{mg} / \mathrm{kg}$. The dose of different fractions was prepared by reconstituting the required quantity of the fraction in Tween 80 (5\% v/v in saline). The freshly prepared drug was administered to Wistar rats through the oral route (p.o.).

\section{In vitro anti-inflammatory study}

\section{Preparation of red blood cells (RBCs) suspension}

Sufficient amount of blood was withdrawn through cardiac puncture under light ether anesthesia, which was then transferred into a glass tube containing $1.8 \mathrm{mg} / \mathrm{ml}$ 5\% ethylenediaminetetraacetic acid solution and mixed tenderly. The collected sample was centrifuged at $3000 \mathrm{rpm}$ for $15 \mathrm{~min}$ and washed 3 times with an equal volume of normal saline. The blood suspension so obtained was measured and suspended in normal saline to obtain $10 \% \mathrm{v} / \mathrm{v}$ suspension. The prepared suspension was stored at $4^{\circ} \mathrm{C}$ and used within $6 \mathrm{~h}$ [8].

\section{Heat-induced hemolysis}

For the estimation, the reaction mixture was prepared in a test tube by placing $1 \mathrm{ml}$ of $10 \%$ RBC suspension and different concentrations of test compound and standard drug. Moreover, for the purpose of control, an equal volume of normal saline was used. All the samples were incubated at $57^{\circ} \mathrm{C}$ for $30 \mathrm{~min}$ over a water bath followed by cooling under running tap water. Afterward, each sample was then centrifuged at $2500 \mathrm{rpm}$ for about $5 \mathrm{~min}$. The supernatant was removed carefully and examine spectrophotometrically at a wavelength of $560 \mathrm{~nm}$.

\section{In vitro anti-arthritic activity}

Inhibition of protein denaturation

For determining the anti-arthritic activity, test solution was prepared by taking $1 \mathrm{ml}$ of bovine serum albumin and $1 \mathrm{ml}$ of test solution while standard solution consists of $1 \mathrm{ml}$ of bovine serum albumin and $1 \mathrm{ml}$ of diclofenac sodium.

The test solution includes fractions of n-hexane, chloroform, ethyl acetate, and n-butanol of leaves of $E$. prostrata. All the above solutions were then adjusted to $\mathrm{pH} 6.3$ using $1 \mathrm{~N} \mathrm{HCl}$. The samples were incubated at $37^{\circ} \mathrm{C}$ for $30 \mathrm{~min}$, and the temperature was increased to keep the samples at $57^{\circ} \mathrm{C}$ for $5 \mathrm{~min}$. The absorbance was measured using UV-Visible spectrophotometer at $660 \mathrm{~nm}$. The control represents $100 \%$ protein denaturation [8].

\section{Proteinase inhibitory activity}

Proteinase inhibitory potential was studied according to the method of Oyedepo et al., 1995, with slight modifications. For the estimation different concentration of test, samples were prepared, which consists of $0.06 \mathrm{mg}$ trypsin, $1 \mathrm{ml} 20 \mathrm{mM}$ Tris $\mathrm{HCl}$, and $1 \mathrm{ml}$ of test solution/ standard solution. All the samples were then incubated at $37^{\circ} \mathrm{C}$ for $5 \mathrm{~min}$, and $1 \mathrm{ml}$ of $0.8 \% \mathrm{w} / \mathrm{v}$ casein was added to the reaction mixture followed by incubation at $37^{\circ} \mathrm{C}$ for $20 \mathrm{~min} .2 \mathrm{ml}$ of perchloric acid $(70 \%)$ was added to each tube for termination of the reaction. All the samples were centrifuged at $3000 \mathrm{rpm}$ for $20 \mathrm{~min}$ and were subjected to UV spectrophotometric analysis at $210 \mathrm{~nm}$ [8].

\section{Membrane stabilization test/inhibition of membrane lysis}

The principle involved here is stabilization of human RBC (HRBC) membrane by hypotonicity induced membrane lysis. The assay mixture contains $1 \mathrm{ml}$ phosphate buffer ( $\mathrm{pH} 7.4,0.15 \mathrm{M}), 2 \mathrm{ml}$ hypo saline $(0.36 \%)$, and $0.5 \mathrm{ml} \mathrm{HRBC}$ suspension $(10 \% \mathrm{v} / \mathrm{v}$ ) with $0.5 \mathrm{ml}$ of plant fractions and standard drug diclofenac sodium of various concentrations $(50,100,250,500,1000$, and $2000 \mu \mathrm{g} / \mathrm{ml})$ and control (distilled water instead of hypo saline to produce $100 \%$ hemolysis) which were incubated at $37^{\circ} \mathrm{C}$ for $30 \mathrm{~min}$ and centrifuged, respectively. The hemoglobin content in the suspension was estimated using spectrophotometer at $560 \mathrm{~nm}$, and percentage inhibition of membrane stabilization can be calculated [8].

\section{In vivo anti-inflammatory study}

Carrageenan-induced paw edema

Wistar albino rats were starved overnight and were divided into 11 different groups, consisting of five animals in each group, according to the treatment given to them. Group I animals are considered as control receiving neither fraction nor carrageenan while Group II (negative control) animals receive the only carrageenan. Groups III and IV received EPHF at the dose of 100 and $200 \mathrm{mg} / \mathrm{kg}$. Similarly, in Groups V and VI, EPCF was administered at the same doses. EPEAF at a dose of 100 and $200 \mathrm{mg} / \mathrm{kg}$ was administered to Groups VII and VIII and EPBF were given to Groups IX and X. Finally, standard drug diclofenac sodium at a dose of $5 \mathrm{mg} / \mathrm{kg}$ was administered to Group XI. To ensure uniform hydration, the rats receive $5 \mathrm{ml}$ of water by stomach tube (controls) or the test drug dissolved/suspended in $5 \% \mathrm{v} / \mathrm{v}$ Tween 80 . Thirty minutes later, the rats were challenged by subcutaneous injection of $0.1 \mathrm{ml}$ of $1 \%$ solution of carrageenan into the plantar side of the left hind paw. The paw is marked with ink at the level of the lateral malleolus and immersed in mercury up to this mark. The paw volume was measured plethysmographically immediately after injection and then after $1 \mathrm{~h}, 2 \mathrm{~h}$, $3 \mathrm{~h}$, and $6 \mathrm{~h}$ and eventually $24 \mathrm{~h}$ after challenge. Results thus obtained for various dosage groups would be further subjected to statistical analysis and were compared with standard and control group [9].

\section{Formaldehyde-induced arthritis}

Wistar rats were starved overnight and divided into seven groups depending on the results obtained in the above model. Each group 
includes five animals. On day 1, $30 \mathrm{~min}$ after the vehicle/standard/test drug administration chronic non-immunological arthritis was induced by subplantar injection of $0.1 \mathrm{ml}$ of $2 \%$ formaldehyde solution and similar treatment was given on day 3 .

Group I animals will be acts as a control group which neither receives any noxious stimulus nor any treatment while in Group II $0.1 \mathrm{ml}$ of $2 \%$ formaldehyde solution is injected in the left paw. Groups III and IV would receive a dose of $100 \mathrm{mg} / \mathrm{kg}$ and $200 \mathrm{mg} / \mathrm{kg}$ of EPA fraction. On the other hand, Groups V and VI received EPCF at similar doses. Finally, Group VII was considered as a standard group which received diclofenac sodium at a dose of $5 \mathrm{mg} / \mathrm{kg}$ [9].

\section{Statistical analysis}

All experiments were conducted in triplicate and values expressed as the mean \pm standard deviation. Variations in mean were calculated using one-way analysis of variance, and means were statistically significant if $\mathrm{p}<0.05$.

\section{RESULTS}

\section{Phytochemical analysis}

Pharmacologically active EPHF, EPCF, EPBF, and EPAF fractions were screened for the phytochemical study. The results are shown in Table 1.

\section{Heat-induced hemolysis}

It is of particular concern to investigate the in vitro anti-inflammatory properties of medicinal plants, especially those traditionally used in folk medicine. In the present study, the stabilization of erythrocyte membranes exposed to heat-induced lyses was employed. The fractions of a hydroalcoholic extract of E. prostrata have shown significant activity at various concentrations, and its effect was compared with the standard drug diclofenac sodium. The chloroform fraction shows an excellent percentage of protection of $64.56 \%$ when compared with the standard. Moreover, EPEAF also shows a good percentage of protection of $62.33 \%$. The maximum percentage membrane stabilization of fractions of E. prostrata was observed at $1000 \mu \mathrm{g} / \mathrm{ml}$, respectively, as shown in Fig. 1, whereas diclofenac sodium shows comparative protection at a concentration of $750 \mu \mathrm{g} / \mathrm{ml}$.

\section{Inhibition of protein denaturation}

Production of autoantigen in certain arthritic disease is due to denaturation of proteins. The mechanism of denaturation involves alteration in electrostatic hydrogen, hydrophobic, and disulfide bonding. From the results of the present study, it can be stated that the fractions of E. prostrata leaves are capable of controlling the production of autoantigen and thereby it inhibits the denaturation of proteins and its effect was compared with the standard drug diclofenac. The maximum percentage of protection was shown by chloroform fraction $(82.16 \%)$ than by the ethyl acetate fraction (81.24\%). From Fig. 2 , it can be clearly observed that chloroform and ethyl acetate fraction exhibits the comparative percentage protection. However, EPBF also showed good inhibition in protein denaturation with percentage activity of 78.38\%. Obtained data showed that EPCF and EPEAF could be used as a potent anti-arthritic agent.

\section{Proteinase inhibitory activity}

Proteinase inhibitory action was studied to establish the mechanism of the anti-arthritic effect of various fractions of E. prostrata. The production of auto-antigens in certain arthritic diseases may be due to proteinase action. From the results depicted in Fig. 3, it reveals that EPCF and EPEAF fractions are capable of inhibiting proteinase action

Table 1: Preliminary phytochemical screening of plant fractions

\begin{tabular}{|c|c|c|c|c|c|c|}
\hline \multirow[t]{2}{*}{ S.No. } & \multirow[t]{2}{*}{ Tested for } & \multirow[t]{2}{*}{ Chemical test } & \multicolumn{4}{|c|}{ Inference } \\
\hline & & & EPHF & EPCF & EPEAF & EPBF \\
\hline \multirow[t]{2}{*}{1} & Acidic compounds & Sodium-bicarbonate test & + & + & - & - \\
\hline & & Litmus test & + & + & - & - \\
\hline \multirow[t]{3}{*}{2} & Alkaloids & Dragons off test & - & - & + & + \\
\hline & & Meyer's test & - & + & + & + \\
\hline & & Wagner's test & - & + & + & + \\
\hline \multirow[t]{2}{*}{3} & Amino acids & Millon's test & - & - & - & + \\
\hline & & Ninhydrin test & - & - & + & + \\
\hline \multirow[t]{3}{*}{4} & Carbohydrates & Molisch's test & + & + & + & + \\
\hline & & Fehling's test & - & + & + & + \\
\hline & & Benedict's test & + & + & + & + \\
\hline 5 & Lignin & Phloroglucinol test & - & - & - & - \\
\hline 6 & Volatile oil & Sudan III test & - & - & + & + \\
\hline 7 & Fats and fixed oil & Sodium hydrogen sulfate & - & + & + & + \\
\hline \multirow{2}{*}{8} & & Lead acetate test & - & + & + & + \\
\hline & & Alkaline reagent test & - & - & + & + \\
\hline \multirow[t]{8}{*}{9} & Glycosides & Borntrager's test & - & - & + & + \\
\hline & & Modified Borntrager's test & - & + & + & + \\
\hline & & Hydroxy anthraquinone & - & - & - & - \\
\hline & & Keller-killini test & - & - & + & + \\
\hline & & Raymond's test & - & - & - & - \\
\hline & & Legal's test & - & - & + & + \\
\hline & & Baljet's test & - & - & - & + \\
\hline & & Froth formation test & - & - & + & + \\
\hline \multirow[t]{4}{*}{10} & Tannins & Ferric chloride test & + & + & + & + \\
\hline & & Gelatin test & + & + & + & + \\
\hline & & Test for catechin & + & + & + & + \\
\hline & & Test for chlorogenic acid & + & + & + & + \\
\hline \multirow[t]{2}{*}{11} & Protein & Biuret test & - & + & + & + \\
\hline & & Hydrolysis test & - & + & + & + \\
\hline
\end{tabular}




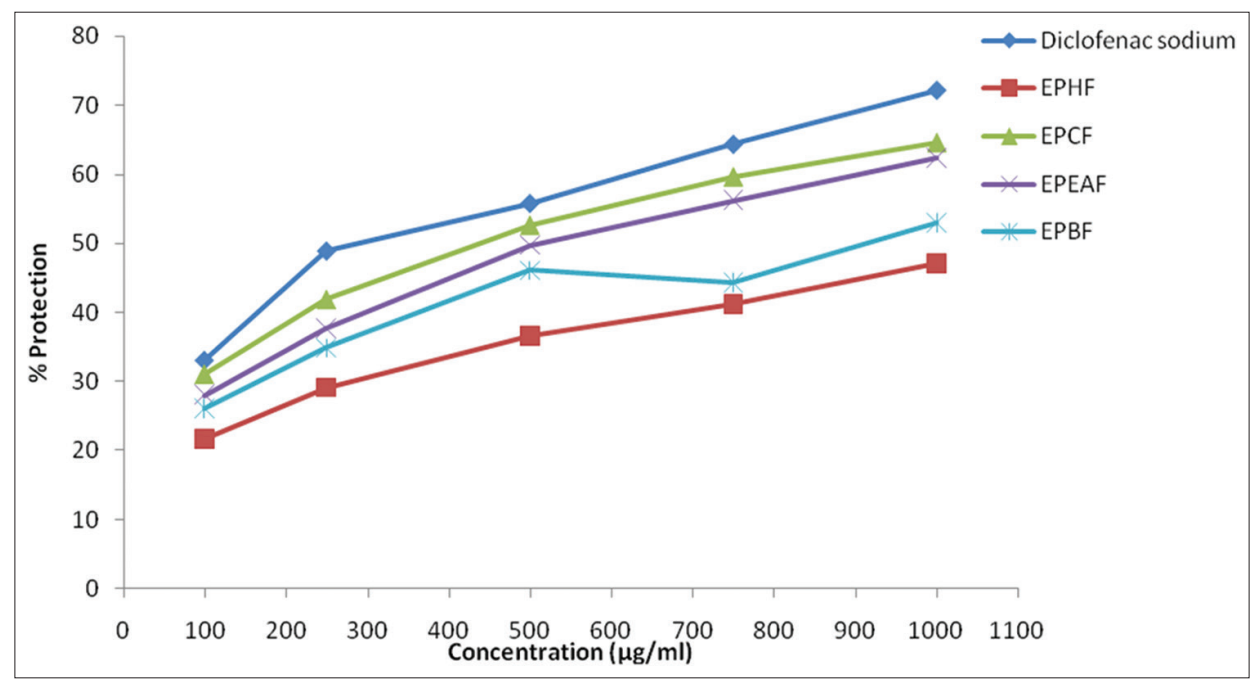

Fig. 1: Comparison of the anti-arthritic activity of fractions of $E$. prostrata and diclofenac sodium on hemolysis

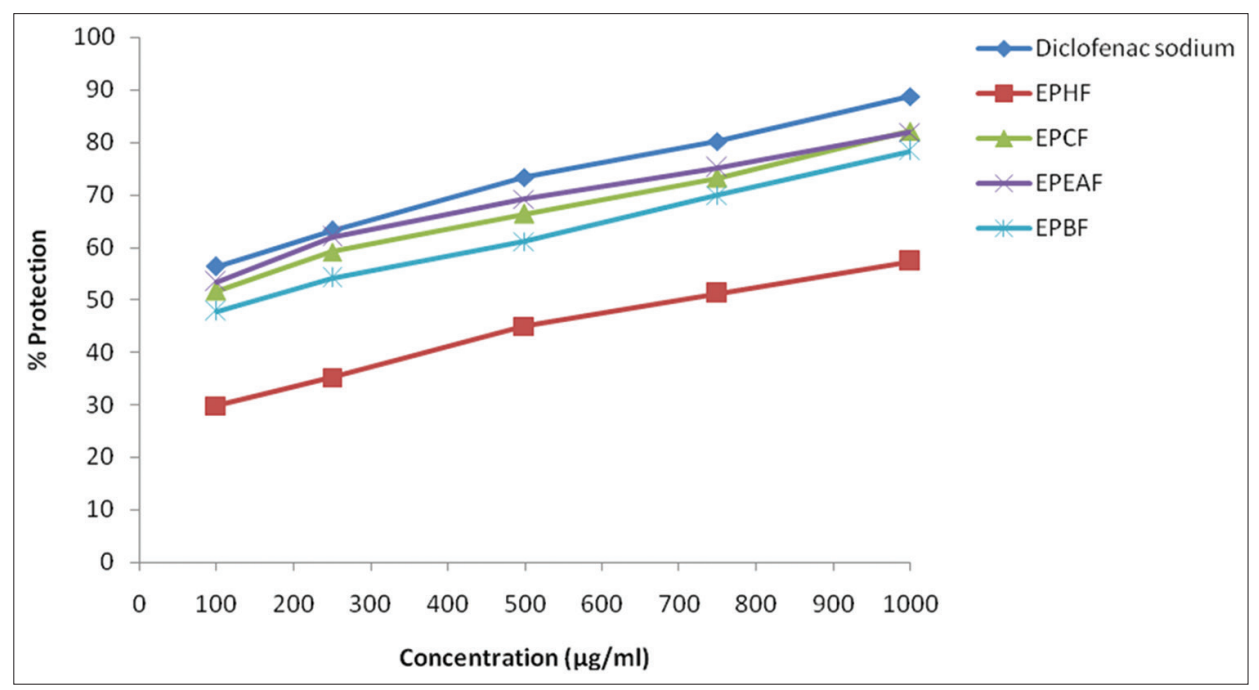

Fig. 2: Comparison of the activity of fractions of E. prostrata and diclofenac sodium on protein denaturation

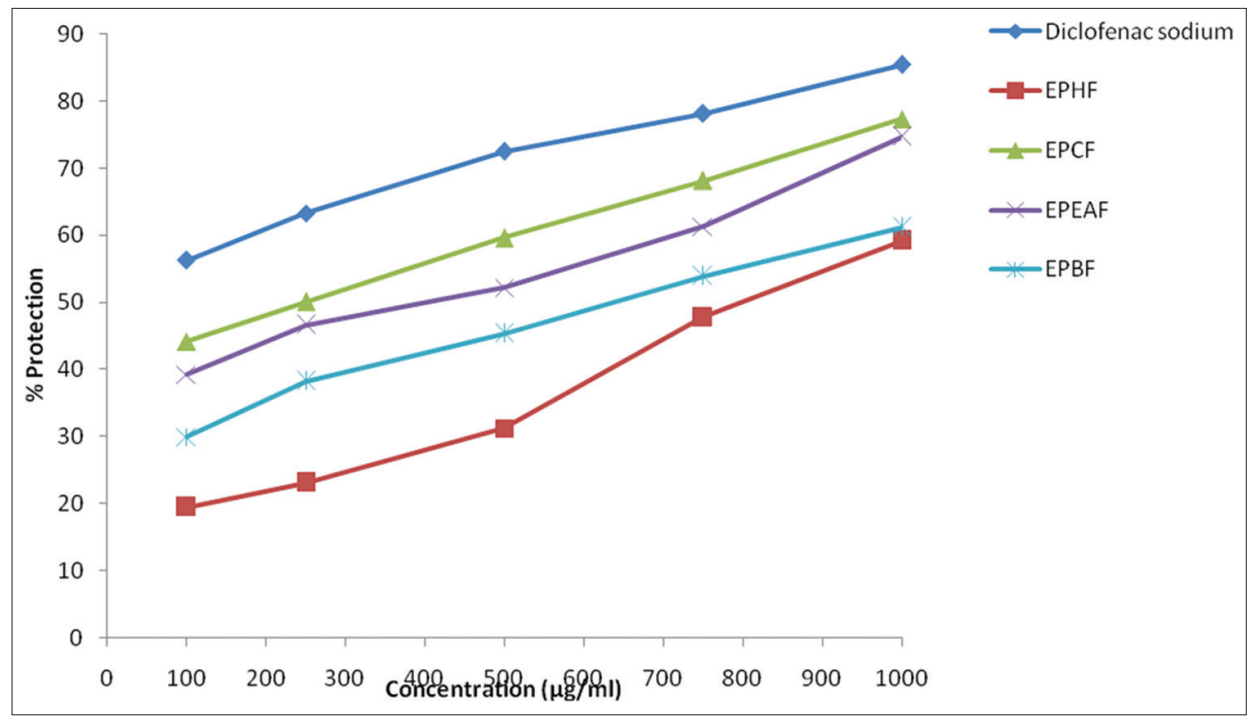

Fig. 3: Comparison of the anti-arthritic activity of fractions of $E$. prostrata and diclofenac sodium on proteinase inhibitory activity

in rheumatic diseases. Moreover, results obtained for the chloroform fraction showed $77.31 \%$ proteinase inhibition when compared with standard diclofenac at a concentration of $1 \mathrm{mg} / \mathrm{ml}$. The percentage inhibition in proteinase inhibitory activity for EPEAF was $74.68 \%$. 


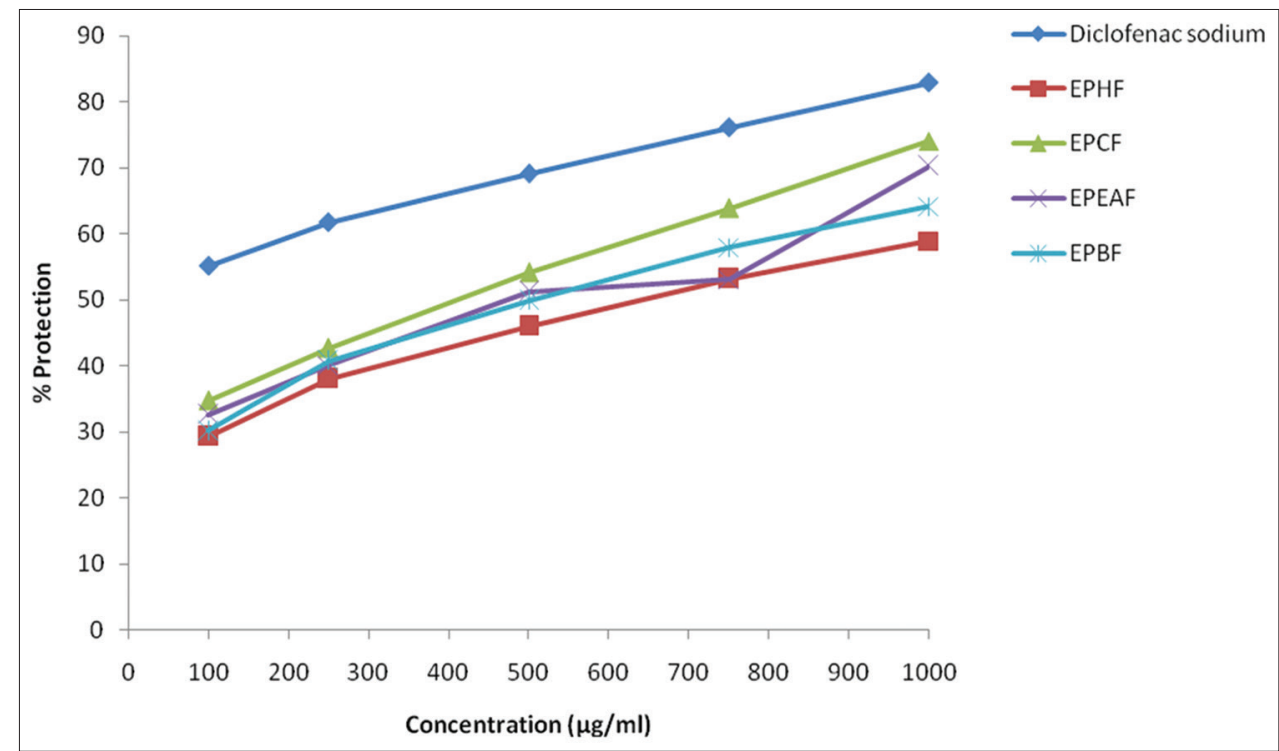

Fig. 4: Comparison of the anti-arthritic activity of fractions of $E$. prostrata and diclofenac sodium on membrane stabilization

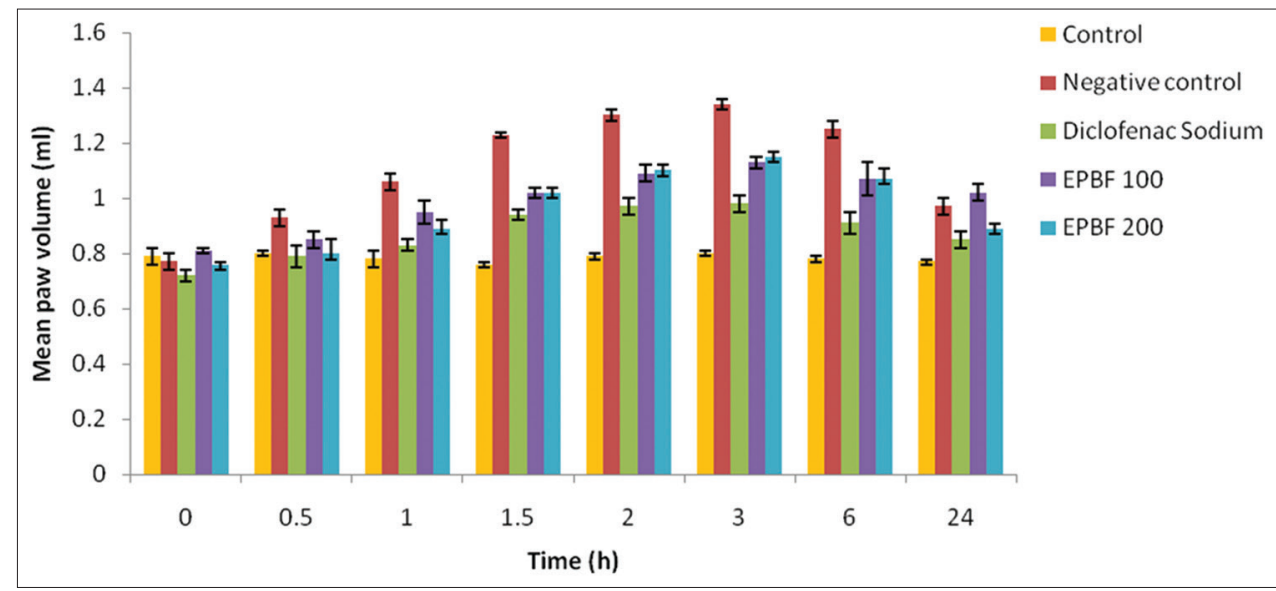

Fig. 5: Anti-inflammatory activity of n-butanol fraction of $E$. prostrata

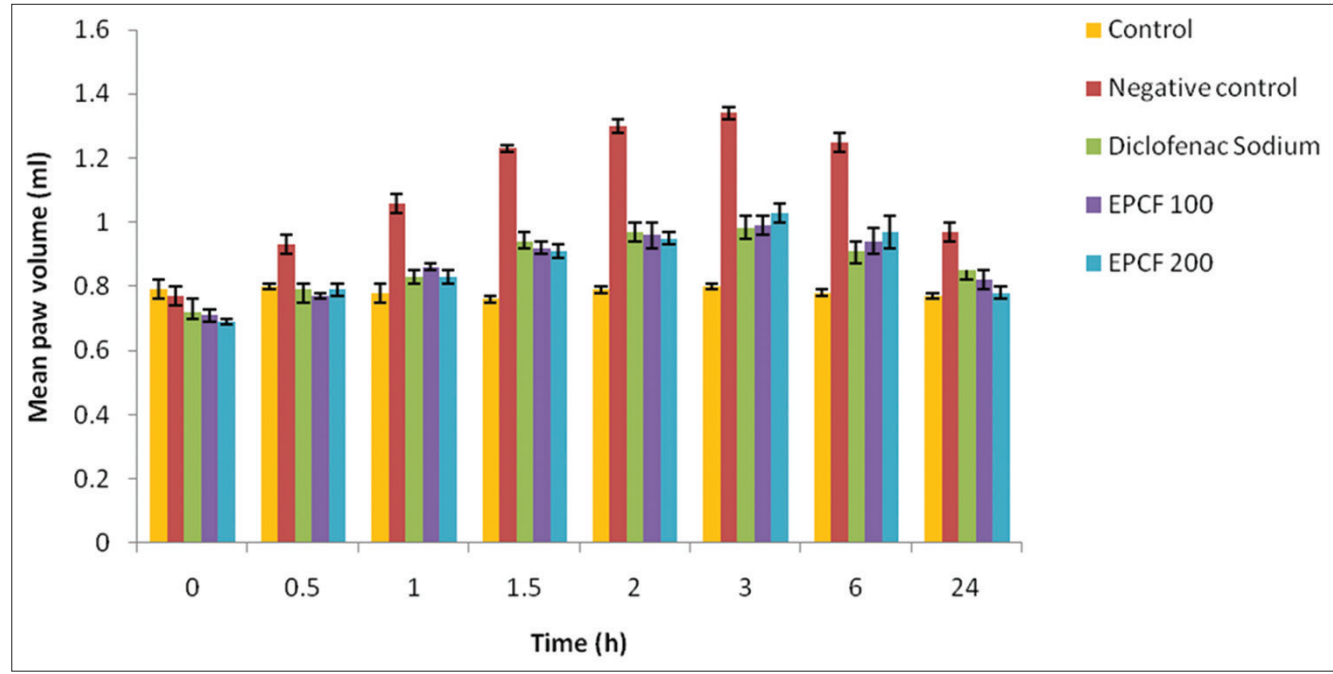

Fig. 6: Anti-inflammatory activity of chloroform fraction of E. prostrata

Membrane stabilization test/Inhibition of membranolysis

In the presentstudy, the stabilization of erythrocyte membranes exposed to hypotonic induced lysis was employed. The erythrocyte membrane is analogous to the lysosomal membrane and its stabilization implies that the extract may as well stabilize lysosomal membranes. The fractions exhibited membrane stabilization effect by inhibiting hypotonicity 


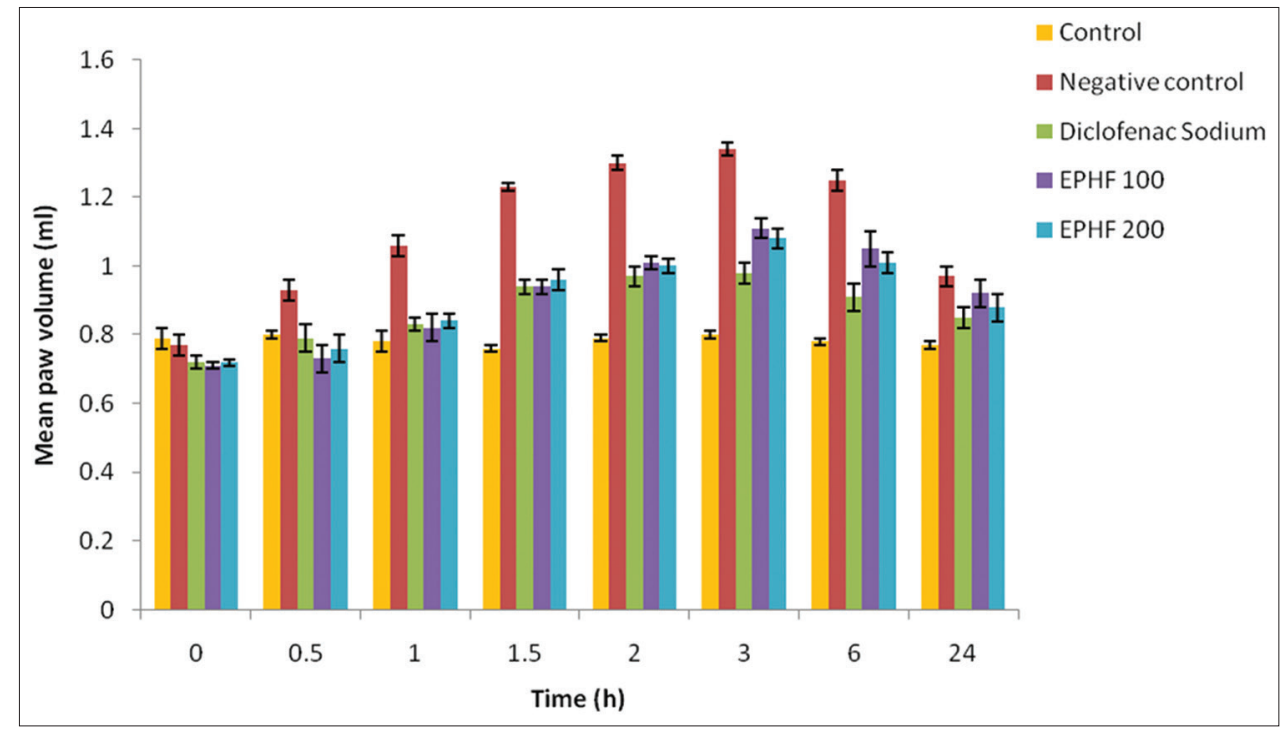

Fig. 7: Anti-inflammatory activity of n-hexane fraction of $E$. prostrata in carrageenan-induced paw edema

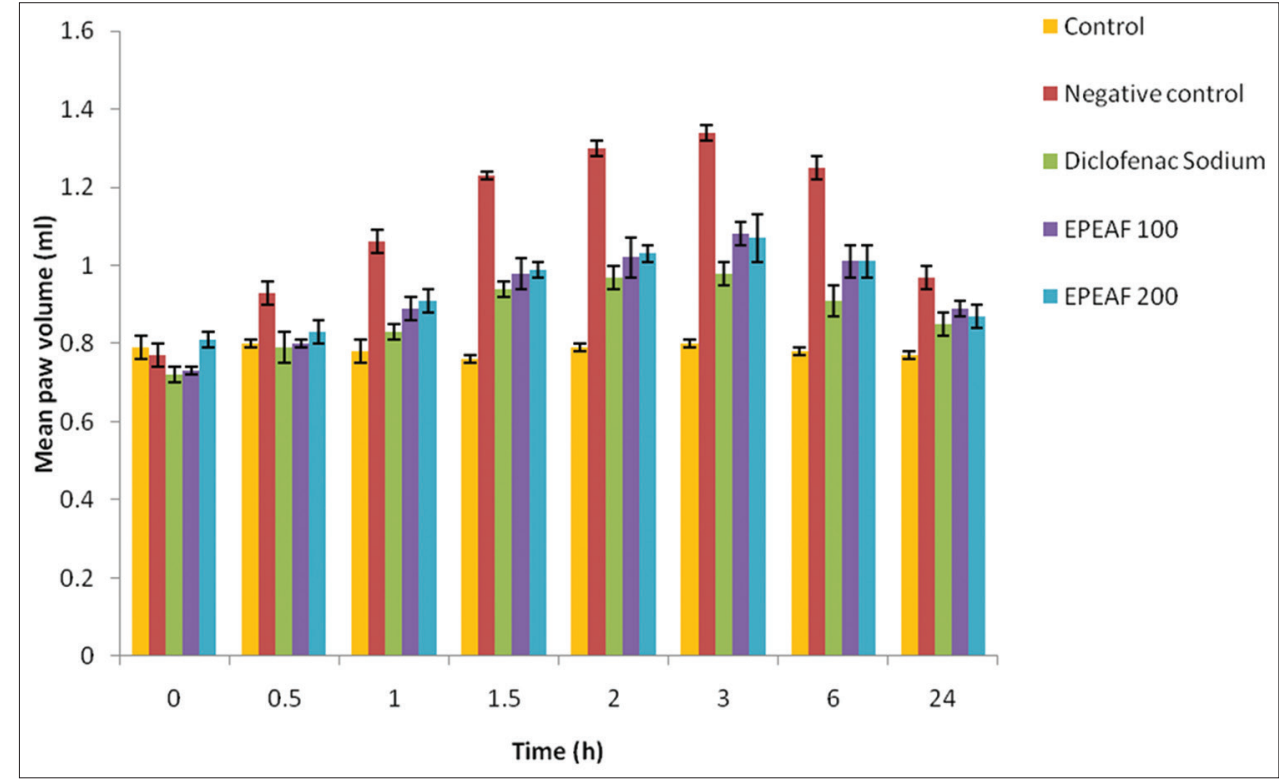

Fig. 8: Anti-inflammatory activity of ethyl acetate fraction of $E$. prostrata

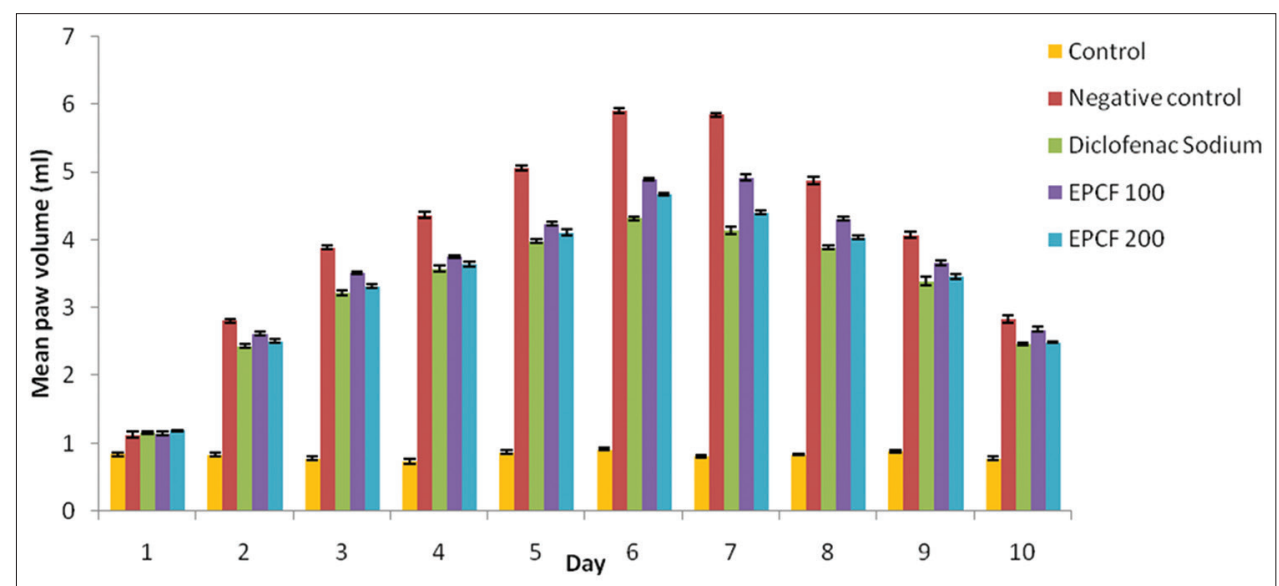

Fig. 9: Anti-arthritic effect of chloroform fraction of $E$. prostrata leaf in formaldehyde induced arthritis model in rats 
induced lysis of the erythrocyte membrane. The chloroform and ethyl acetate fractions of $E$. prostrata had shown significant activity at various concentrations, and its effect was compared with the standard drug diclofenac. In the case of ethyl acetate fraction, the percentage scavenging activity at a concentration of $750 \mu \mathrm{g} / \mathrm{ml}$ does not show a dose-dependent increase in the activity, while chloroform, n-butanol, and n-hexane fraction show a dose-dependent activity. At certain concentration, the EPEAF and EPBF exhibit similar percentage scavenging activity. The maximum percentage membrane stabilization of EPCF and EPEAF was observed as 74.07 and 70.24, respectively, at a concentration of $1000 \mu \mathrm{g} / \mathrm{ml}$. The results are depicted in Fig. 4.

\section{Carrageenan-induced paw edema}

The anti-inflammatory potential of $\mathrm{n}$-hexane, chloroform, ethyl acetate, and n-butanol fraction of hydroalcoholic extract of leaves of E. prostrata was investigated using the carrageenan-induced paw edema method. As shown in Table 2, the fractions obtained from hydroalcoholic extract at doses of 100 and $200 \mathrm{mg} / \mathrm{kg}$ body weight showed significant and dose-dependent inhibition in inflammation induced by carrageenan. The maximum inflammation was seen after $3 \mathrm{~h}$ of injecting carrageenan in paw in each group.

As depicted in Fig. 5 the EPBF does not reduce paw inflammation significantly with standard while EPCF shows a more significant reduction in paw volume with respect to diclofenac as mentioned in Fig. 6. Whereas EPHF and EPEAF has show somewhat reduction in paw volume as depicted in Figs 7 and 8.

The results revealed that chloroform and ethyl acetate fraction at a dose of $200 \mathrm{mg} / \mathrm{kg}$ show maximum inhibition of inflammation of $26.92 \%$ and $23.86 \%$, respectively. In addition, n-hexane $(22.76 \%)$ and n-butanol $(17.07 \%)$ fractions also show significant inhibition of inflammation in carrageenan-induced paw edema model when compared with standard. However, standard drug (diclofenac sodium, $5 \mathrm{mg} / \mathrm{kg}$ ) showed highly significant inhibition at the same time with the maximum percentage inhibition when compared to the control group, as shown in Table 3.

\section{Formaldehyde-induced arthritis}

The figures obtained from the carrageenan-induced paw edema model showed that chloroform and ethyl acetate fraction have maximum antiinflammatory activity. Thus in formaldehyde induced arthritis models, the anti-arthritic potential of EPCF and EPEAF would be evaluated. The formaldehyde test is a sensitive and valid model for various classes of anti-arthritic drugs. It produces a biphasic response and different drugs may act differently in the early and late phase of the test. The effects of EPCF and EPEAF at the dose of 100 and $200 \mathrm{mg} / \mathrm{kg}$ on formaldehyde induced arthritis are shown in Table 4. The data depicted in Tables 4 and 5 showed that EPCF at both doses exhibits significant anti-arthritic activity, while EPEAF at a dose of $100 \mathrm{mg} / \mathrm{kg}$ had a lesser anti-arthritic activity than $200 \mathrm{mg} / \mathrm{kg}$ when compared to control.

In the negative control group, the foot volume reached its maximum value on the $7^{\text {th }}$ day and thereafter decreased slightly by the $8^{\text {th }}$ day. As depicted in Fig. 9 the animals treated with EPCF (100 and $200 \mathrm{mg}$ / $\mathrm{kg}$ ) showed maximum swelling on the $5^{\text {th }}$ day, and the foot volume was reduced on the $9^{\text {th }}$ day. In EPEAF $(200 \mathrm{mg} / \mathrm{kg})$ treated animals maximum swelling was noticed on the $6^{\text {th }}$ day and then decline in paw volume was observed till the end of the study which is clearly observed from Fig. 10.

\section{DISCUSSION}

Eclipta herbs have been commonly used to treat joint pain and arthritis worldwide. In this study, we investigated the anti-inflammatory and anti-arthritic effects of $E$. prostrata fraction. Plant-derived drug has been demonstrated to contain principles that possess the ability to facilitate the stability of biological membranes when exposed to induced lysis. EPCF and EPEAF were found to possess very good membrane stabilizing property, which is one of the preliminary steps involved in the screening of anti-inflammatory and anti-arthritic property. The mode of action of the extracts and standard anti-inflammatory drugs could be connected

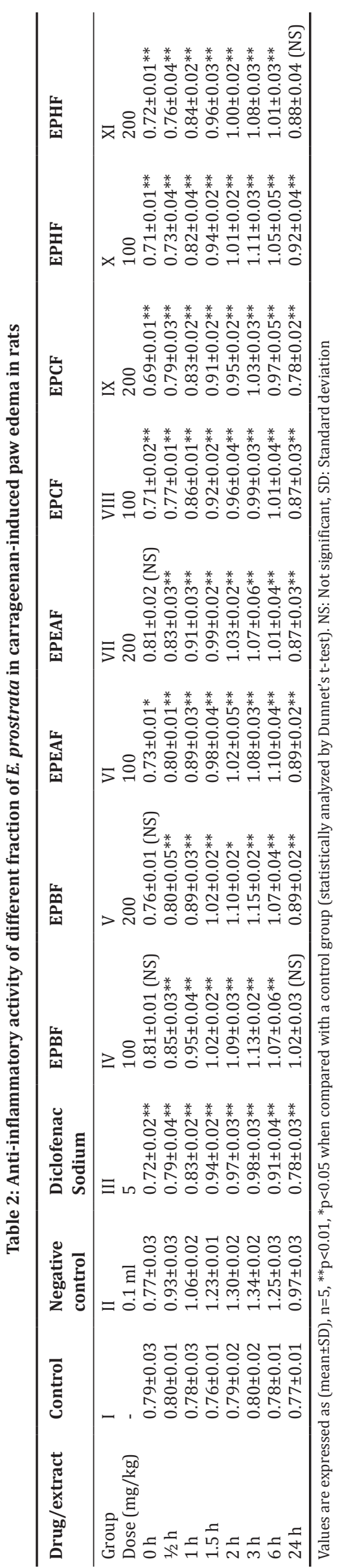




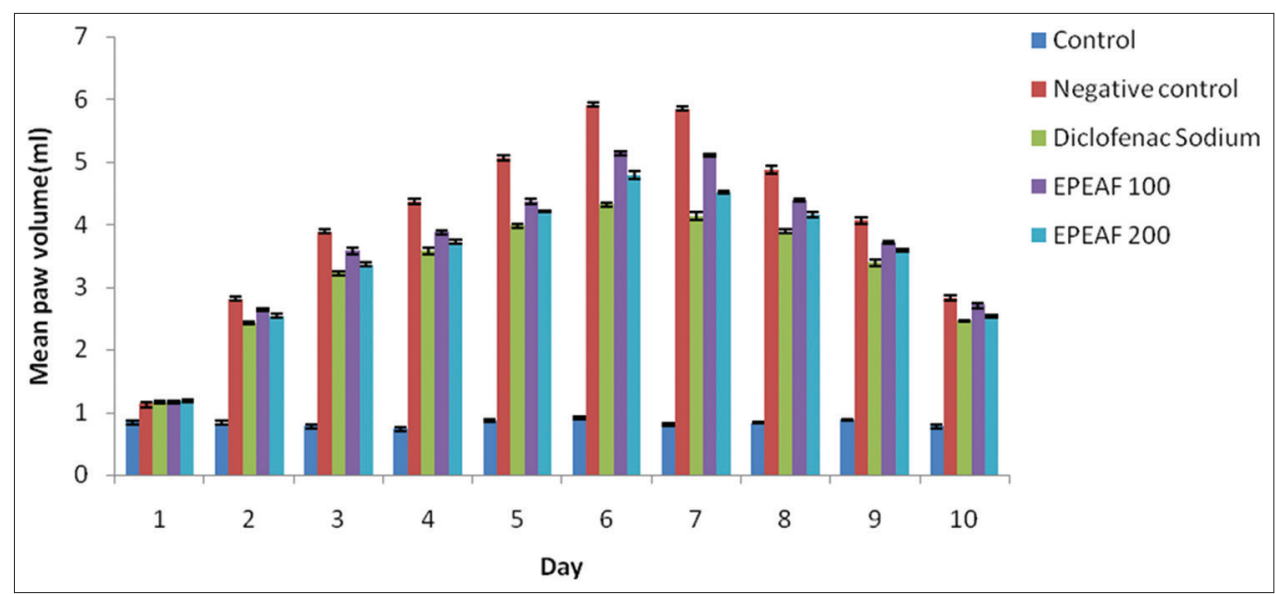

Fig. 10: Anti-arthritic effect of ethyl acetate fraction of E. prostrata leaf in formaldehyde induced arthritis model in rats

Table 3: Percentage Inhibitory effect of n-hexane, chloroform, ethyl acetate, and n-butanol fractions of Eclipta prostrata leaves against carrageenan-induced paw edema in rats

\begin{tabular}{|c|c|c|c|c|c|c|c|c|c|}
\hline \multirow[t]{2}{*}{ Drug } & \multirow[t]{2}{*}{ Dose (mg/kg) } & \multicolumn{8}{|c|}{ Percentage inhibition in paw volume } \\
\hline & & $\mathbf{O} \mathbf{h}$ & $1 / 2 h$ & $1 \mathrm{~h}$ & $1.5 \mathrm{~h}$ & $2 \mathrm{~h}$ & $3 \mathrm{~h}$ & $6 \mathrm{~h}$ & $24 \mathrm{~h}$ \\
\hline Diclofenac sodium & 5 & 6.94 & 15.05 & 21.69 & 23.57 & 25.38 & 36.73 & 27.2 & 19.58 \\
\hline EPHF & 100 & 7.79 & 21.50 & 22.64 & 23.57 & 22.30 & 20.72 & 16.00 & 5.15 \\
\hline EPHF & 200 & 8.86 & 18.25 & 20.75 & 22.76 & 21.95 & 19.40 & 19.26 & 9.27 \\
\hline EPCF & 100 & 7.79 & 17.20 & 18.86 & 25.20 & 26.15 & 26.11 & 24.8 & 15.46 \\
\hline EPCF & 200 & 10.38 & 15.05 & 21.69 & 26.01 & 26.92 & 23.13 & 22.4 & 19.58 \\
\hline EPEAF & 100 & 5.94 & 13.97 & 16.03 & 20.32 & 21.53 & 19.40 & 18.04 & 8.20 \\
\hline EPEAF & 200 & 5.19 & 10.75 & 14.15 & 19.51 & 20.76 & 23.86 & 19.20 & 10.30 \\
\hline EPBF & 100 & 5.19 & 8.6 & 10.37 & 17.07 & 16.15 & 15.67 & 14.40 & 5.15 \\
\hline EPBF & 200 & 1.29 & 3.61 & 16.03 & 17.07 & 15.38 & 14.17 & 14.10 & 8.2 \\
\hline
\end{tabular}

Table 4: Anti-arthritic activity of chloroform and ethyl acetate fraction of $E$. prostrata in formaldehyde induced arthritis

\begin{tabular}{|c|c|c|c|c|c|c|c|}
\hline Treatment & Control & Negative control & Diclofenac sodium & EPCF & EPCF & EPEAF & EPEAF \\
\hline Groups & $\mathbf{I}$ & II & III & IV & $\mathbf{v}$ & VI & VII \\
\hline $\begin{array}{l}\text { Dose } \\
\text { Mean PAW } \\
\text { volume (ml) }\end{array}$ & - & $0.1 \mathrm{ml}$ & $5 \mathrm{mg} / \mathrm{kg}$ & $100 \mathrm{mg} / \mathrm{kg}$ & $200 \mathrm{mg} / \mathrm{kg}$ & $100 \mathrm{mg} / \mathrm{kg}$ & $200 \mathrm{mg} / \mathrm{kg}$ \\
\hline Day 1 & $0.84 \pm 0.03^{* *}$ & $1.13 \pm 0.04$ & $1.16 \pm 0.02(\mathrm{NS})$ & $1.14 \pm 0.03(\mathrm{NS})$ & $1.19 \pm 0.01^{* *}$ & $1.17 \pm 0.02(\mathrm{NS})$ & $1.18 \pm 0.02 *$ \\
\hline Day 2 & $0.83 \pm 0.3^{* *}$ & $2.81 \pm 0.03$ & $2.43 \pm 0.03^{* *}$ & $2.62 \pm 0.02(\mathrm{NS})$ & $2.51 \pm 0.03^{* *}$ & $2.64 \pm 0.02(\mathrm{NS})$ & $2.54 \pm 0.03^{*}$ \\
\hline Day 3 & $0.78 \pm 0.03^{* *}$ & $3.89 \pm 0.03$ & $3.22 \pm 0.04^{* *}$ & $3.52 \pm 0.02 * *$ & $3.32 \pm 0.02 * *$ & $3.58 \pm 0.06 * *$ & $3.36 \pm 0.03^{* *}$ \\
\hline Day 4 & $0.73 \pm 0.03^{* *}$ & $4.37 \pm 0.04$ & $3.58 \pm 0.05^{* *}$ & $3.75 \pm 0.02^{* *}$ & $3.64 \pm 0.04 * *$ & $3.87 \pm 0.03^{* *}$ & $3.72 \pm 0.03^{* *}$ \\
\hline Day 5 & $0.87 \pm 0.03^{* *}$ & $5.06 \pm 0.04$ & $3.98 \pm 0.03^{* *}$ & $4.24 \pm 0.03^{* *}$ & $4.11 \pm 0.04^{* *}$ & $4.360 .04^{* *}$ & $4.21 \pm 0.02^{* *}$ \\
\hline Day 6 & $0.91 \pm 0.02 * *$ & $5.91 \pm 0.03$ & $4.32 \pm 0.03^{* *}$ & $4.90 \pm 0.02^{* *}$ & $4.67 \pm 0.02 * *$ & $5.14 \pm 0.03^{* *}$ & $4.79 \pm 0.07^{* *}$ \\
\hline Day 7 & $0.81 \pm 0.02^{* *}$ & $5.85 \pm 0.03$ & $4.14 \pm 0.05^{* *}$ & $4.92 \pm 0.04^{* *}$ & $4.40 \pm 0.03^{* *}$ & $5.10 \pm 0.02 * *$ & $4.51 \pm 0.02^{* *}$ \\
\hline Day 8 & $0.83 \pm 0.01^{* *}$ & $4.88 \pm 0.06$ & $3.89 \pm 0.03^{* *}$ & $4.31 \pm 0.03^{* *}$ & $4.04 \pm 0.03^{* *}$ & $4.39 \pm 0.03^{* *}$ & $4.15 \pm 0.04^{* *}$ \\
\hline Day 9 & $0.88 \pm 0.02 * *$ & $4.07 \pm 0.05$ & $3.39 \pm 0.06^{* *}$ & $3.66 \pm 0.03^{* *}$ & $3.46 \pm 0.04^{* *}$ & $3.71 \pm 0.02 * *$ & $3.58 \pm 0.02 * *$ \\
\hline Day 10 & $0.78 \pm 0.03^{* *}$ & $2.83 \pm 0.05$ & $2.46 \pm 0.02 * *$ & $2.68 \pm 0.04^{* *}$ & $2.49 \pm 0.01^{* *}$ & $2.71 \pm 0.04^{* *}$ & $2.54 \pm 0.02^{* *}$ \\
\hline
\end{tabular}

Values are expressed as (mean $\pm \mathrm{SD}$ ), $\mathrm{n}=5,{ }^{* *} \mathrm{p}<0.01,{ }^{*} \mathrm{p}<0.05$ when compared with the control group (statistically analyzed by Dunnet's t-test). NS: Not significant,

SD: Standard deviation

Table 5: Inhibitory effect of chloroform and ethyl acetate fraction of Eclipta prostrata in formaldehyde induced arthritis in rats

\begin{tabular}{|c|c|c|c|c|c|c|c|c|c|c|}
\hline \multirow[t]{2}{*}{ Drug/extract } & \multicolumn{10}{|c|}{ Percentage inhibition in paw volume } \\
\hline & Day 1 & 2 & 3 & 4 & 5 & 6 & 7 & 8 & 9 & 10 \\
\hline Diclofenac sodium & 2.65 & 13.52 & 17.22 & 19.91 & 21.34 & 26.90 & 29.23 & 20.28 & 16.70 & 13.07 \\
\hline EPCF (200 mg/kg) & 5.30 & 10.67 & 14.65 & 16.70 & 18.77 & 20.98 & 24.78 & 17.21 & 14.98 & 12.01 \\
\hline EPEAF (100 mg/kg) & 3.53 & 6.04 & 8.65 & 11.44 & 16.05 & 13.02 & 12.82 & 10.04 & 8.84 & 4.24 \\
\hline EPEAF (200 mg/kg) & 4.42 & 9.61 & 15.77 & 17.47 & 16.79 & 18.95 & 22.90 & 14.95 & 12.03 & 10.24 \\
\hline
\end{tabular}

with binding to the erythrocyte membranes with subsequent alteration of the surface charges of the cells. This might have prevented physical interaction with aggregating agents or promote dispersal by the mutual repulsion of like charges which are involved in the hemolysis of RBCs. It has been reported that certain saponins and flavonoids exerted a profound stabilizing effect on lysosomal membrane both in vivo and in vitro, 
while tannins and saponins possess the ability to bind cations, thereby stabilizing erythrocyte membranes and other biological macromolecules.

Proteinases have been implicated in arthritic reactions. Neutrophils are known to be a rich source of proteinase which carries in their lysosomal granules many serine proteinases. It was previously reported that leukocytes proteinase play an important role in the development of tissue damage during inflammatory reactions and significant level of protection was provided by proteinase inhibitors. Inhibition of protein denaturation and proteinase inhibitory action was studied to establish the mechanism of the anti-arthritic effect of fractions of E. prostrata. Hence, the anti-arthritic effect of EPCF and EPEAF was studied significantly using in vitro models, and it can be concluded that both the fractions can serve as an anti-arthritic agent.

The anti-inflammatory effects of the herb were assessed by swelling in the left foot of the rat induced through carrageenan solution. First, substantial inflammation was induced in the lateral left foot, as demonstrated by increased paw volume. The study was conducted to evaluate the anti-inflammatory potential of E. prostrata in laboratory animals using carrageenan-induced paw edema, anti-inflammatory models. Carrageenan-induced rat paw edema model is a widely accepted model for the study of anti-inflammatory activity of compounds. Edema was induced in the left paw of rats following subplantar injection of $0.1 \mathrm{ml}$ of $1 \%$ solution of carrageenan, which results in inflammation due to the release of serotonin, histamine, and prostaglandin-like substances. Oral administration of the four fractions of E. prostrata at a dose of 100 and $200 \mathrm{mg} / \mathrm{kg}$ significantly suppressed inflammation, and the reductions were $26.92 \%, 23.86 \%, 22.76 \%$, and $17.07 \%$ for chloroform, ethyl acetate, n-hexane, and butanol fractions, respectively, at the end of treatment.

Based on the results obtained for the fractions of E. prostrata in the above method, EPCF and EPEAF were examined for their anti-arthritic potential by formaldehyde-induced arthritis in rats. Estimation of the ability of fractions to inhibit formaldehyde-induced edema in rats is documented as the most suitable method for screening anti-arthritic compounds. In rat foot, when formaldehyde was injected, it produces localized inflammation and pain when injected into the paw of rat, which is biphasic comprising of early neurogenic component and a later tissue mediated response. The result of the formaldehyde-induced arthritis study showed both dose- and time-dependent reduction of the paw thickness by both the fractions as well as the reference drug and therefore suggests that chloroform fraction and ethyl acetate fractions of $E$. prostrata may be effective in the management of arthritis.

\section{CONCLUSION}

In the view of above discussion, it is conceivable that E. prostrata has been observed to exert significant anti-arthritic effect in experimental studies. Furthermore, ethyl acetate and chloroform fraction has been reported to be most potent. In summary, this contemporary research lends pharmacological support to reported folkloric usage of plant in the treatment and management of painful arthritic inflammatory conditions. Based on our results, further thorough studies are required for appraisal of exact mechanism of action, determination of pro-inflammatory cytokines level, isolation of active constituents and cellular characterization that could conclusively establish E. prostrata as a potentially safer disease modifying agent in the treatment of RA.

\section{CONFLICTS OF INTEREST}

The authors declare that the research was conducted in the absence of any commercial or financial relationships that could be construed as a potential conflict of interest.

\section{AUTHORS' CONTRIBUTIONS}

All the authors contributed equally in research work. All authors read and approved the final manuscript.

\section{ACKNOWLEDGMENT}

The authors would also acknowledge Director, Institute of Pharmaceutical Sciences, Kurukshetra University, Kurukshetra, for providing necessary facilities for carrying out this work.

\section{REFERENCES}

1. Winslow LC, Kroll DJ. Herbs as medicine. Arch Internal Med 1998;158:2192-9.

2. Mudur G. Panel defends India's traditional doctors. Br Med J 1997;314:1573.

3. Vickers A, Zollman C. ABC of complementary medicine: Herbal medicine. Br Med J 1999;319:1050-3.

4. Firestein GS. Evolving concepts of rheumatoid arthritis. Nature 2003;423:356-61.

5. Kamboj VP. Herbal medicine. Curr Sci 2000;78:35-9.

6. Setty AR, Sigal LH. Herbal medications commonly used in the practice of rheumatology: Mechanisms of action, efficacy, and side effects. Semin Arthritis Rheum 2005;34:773-84.

7. Trease GE, Evans WC. Textbook of Pharmacognosy. $13^{\text {th }}$ ed. Oxford: Alden Press; 1989.

8. Chippada SC, Vanaspati M. Antioxidant, an anti-inflammatory and anti-arthritic activity of Centella asiatica extracts. J Chem Biol Phys Sci 2011;1:260-9.

9. Vogel HG. Drug Discovery and Evaluations. $2^{\text {nd }}$ ed. New York: Springer-Verlag Berlin Heidelberg; 2002. 